\title{
Analysis of Key Issues about Resolving the Local Debt Using the PPP Model
}

\author{
Yaling $\mathrm{DU}^{1, \mathrm{a}}$, Xin $\mathrm{ZHAO}^{1, \mathrm{~b}}$ \\ ${ }^{1}$ School of Management, Tianjin University of Technology, Tianjin 300384, China \\ atdduyaling@126.com, bzhaoxin_901019@163.com
}

Keywords: PPP, Local Debt, VFM, PPP Projects Procurement, Performance Evaluation

\begin{abstract}
PPP model has becamed the important way to relieve local debt. However, it is worth to rethink that how to avoid the new contingent liabilities beyond the prescribed scope caused by PPP projects which is paid or subsidized by government. Three mechanism of relieve local debt is analyzed in strategy level by PPP model, namely decision-making mechanism of PPP projects based on VFM, supervision mechanisms of PPP projects based on the information disclosure, accountability Mechanism of PPP Projects. Three key problems of establish and perfect variety of mechanism are recognized, and executiry advices for above problems are presented. The Department of Finance can reference the conclusion of research to manage PPP project uniformly.
\end{abstract}

\section{Introduction}

One of reasons for Chinese government to promote PPP model is intend to relieve local government debt. Therefore, it is worth reviewing how to avoid new contingent liabilities caused by PPP projects which are paid or given appropriate subsidies by government. Although it is important that some project-level works are done well by the Department of Finance, for example, reasonable risk-sharing, improving projects contract documents, setting and adjusting price scientifically and so on. In addition, it is more important that strategic level works should be done well by the Department of Finance which manages PPP projects.

\section{Decision-making mechanism of PPP projects based on VFM}

2.1 The decision-making mechanism of PPP project based on VFM.The primary way of sponsoring the PPP project is collecting the potential PPP projects among the government functional departments by the Department of Finance and the private sectors should be also given the right to recommend the potential PPP projects. The Department of Finance is given one or two times to collect the report of public requirement or project proposals within the time allowed. The government functional departments should report the projects meeting the requirements on the basis of combing the local economy, social development plan with the industry plan. The requirements include: (1) The industry within the jurisdiction of the departments are in badly need of the PPP projects; (2) Large funds is needed, but the department is short of funds; (3) The supply efficiency of public goods or public service can be improved significantly after the intervention of private sectors. In the case of private sectors, they should try to find out the public demand that government departments neglect or failed to meet in their daily business activities, and the project submitted in written form should meet the following conditions: (1) the field involved should belong to the main business of themselves and their specialty; (2) There exists the public demand that the government have not provided; (3) The supply efficiency of public goods or public service provided by government is low. In order to encourage private sectors to recommend potential PPP projects, if the project pass the screening, assessment and other steps, we advise the Department of Finance give priority to the private sectors that recommend the project to make a successful bid under the same conditions.

2.2 Screening and sorting PPP projects. The Department of Finance determine the list of alternative PPP projects through screening and sorting the projects collected and then formulate the annual and medium-term development plan. The PPP projects in list are evaluated from the 
qualitative and quantitative aspects through the method of Value for Money. The qualitative evaluation should focus on whether the PPP project can reduce the life cycle cost and improve the supply efficiency of public goods compared with the traditional government procurement modes. According to the related date, using the PPP mode doesn't necessarily save money for the government and more importantly it can improve the supply efficiency of the public service. What's more, it also depends on whether the PPP mode can promote innovation and competition. The international methods of quantitative evaluation mainly include Cost-Benefit Analysis (CBA), Public Sector Comparator (PSC), Outline Business Case (OBC) ${ }^{[1]}$, and PSC is much mature and universal. The PSC determine a specific value through comparing the present value of the life cycle cost paid by the government with the public sector. If the specific value of the project is larger than zero, the project can be fitted into the alternative project libraries and the larger the value, the greater the priority. At the same time, the degree that the development is needed in different areas and industries include urgency and significance should be considered when ordering the projects.

2.3 Maintenance of the alternative project library. Projects whose VFM is larger than zero and be selected into the alternative project libraries should be started in sequence according to their rank and the situation of finance, because that there is no way to complete all projects at the same time on account of the limited financial capacity. And appropriate projects are extracted from the alternative project library to constitute the list of alternative PPP projects. Projects that failed to enter the list this time and continue remain in the alternative project library should be managed dynamically, which is maintenance of the alternative project library. This paper argues that the Department of Finance should ensure that the alternative project library information are true, effective, and be cleaned-up regularly. The following cases should be removed from the library promptly: (1) projects that has been revoke or ordered forbid by authority; (2) projects that can't continue to implement due to force majeure influences, or was found to have serious behavior in violation of state laws and regulations; (3) projects that have not entered into the list after entering alternative project X years. In addition, projects which have preserved after cleaning also should be reordered with the library projects, considering the change of market environment and industry development.

\section{Supervision mechanisms of PPP projects based on the information disclosure}

3.1 The supervision of public products quality. It is necessary for the government to control public product quality of PPP projects in order to ensure public welfare objectives of the project considering different purpose between the government and private sectors which means the former is to improve the Public Products' supply efficiency and the later aims to make profit. This paper recommends that the Department of Finance should urge the government departments to do the following things: (1)define or develop quality standards of public products clearly to be proof of the output performance of PPP projects. (2) Make management methods for quality of public product to be evidence-based for supervision, which mainly makes regular checks of public product, including provisions of testing frequency and feedback of test results. (3)Perfect annual and quarterly output performance system of the PPP projects to ensure the normal operation of the PPP projects and provide data for optimization of the government various functional departments.

3.2 Supervision of private sectors profitability. It is necessary for The Department of Finance to understand and grasp the profitability of private sectors in PPP projects. This paper argues that: (1) require SPV to provide project's each annual and quarterly financial report, and to be responsible for the authenticity; (2)According to financial data reported, the Department of Finance determine the profitability of the PPP project in the current period. As for the condition that private sectors' "profiteering" or "loss" proceed to a certain extent, we can establish the appropriate price or subsidy adjustment scheme as needed, even set sharing mechanism of excess return; (3) The Department of Finance can also audit SPV of the PPP project by random sample, and they will punish or even hold liable fraud cases. 
3.3 The information disclosure of the PPP project. Chinese Government aims to introduce competition and innovation to the public domain through the promotion of PPP with a premise that the whole process of implementation should be open and transparent; otherwise the PPP model is likely to produce more collusion between the Government officials and private sectors. Information disclosure is indispensable in the promotion of PPP. Private sectors should disclose the quantity and quality of the PPP project output, project's management state and other information; the government should open PPP project contractual terms, performance monitoring report, mid-term evaluation report, the major changes and termination of the project not involved the state secrets and the trade secrets etc. In addition, the public is the ultimate user of the PPP project, therefore, the Department of Finance can establish report mechanism of public prize contain via telephone and internet to encourage citizens to participate in the discussion actively and rationality.

\section{Accountability Mechanism of PPP Projects}

4.1 Determination of performance evaluation indices of PPP projects. It is the key for the Department of Finance to determine how to evaluate the performance of PPP projects, making it more scientific and more conducive to the development of follow-up PPP projects, namely the performance evaluation indices of PPP projects. Different from the projects in traditional mode, PPP projects lay emphasis on the value of money, innovation and establishment of partnership; therefore, it will be more complex for the performance evaluation indices of PPP projects, requiring reflecting different project phases with different work properties as well as combining short-term interests with long-term interests. Relevant scholars have attempted to establish the Key Performance Indices

(KPI) of PPP projects, including the static indices reflecting physical features of PPP projects and the dynamic indices reflecting the needs of interest parties in economy, innovation, culture, benefit sharing and so on ${ }^{[2]}$. In addition, some scholars suggested that the balanced scorecard evaluation system in 5 dimensions of project environment, satisfaction of interest parties, financial capability, internal control management, innovation and growth should be established based on the strategic objectives of PPP projects and regarding the third party, which is relatively independent, as the subject of evaluation ${ }^{[3]}$. However, practice is far more complex than theory, and much still remains to be done to establish a scientific performance evaluation index system of PPP projects.

4.2 Experience summary of favorable PPP projects. Currently, the Department of Finance should recommend specific practices of the PPP projects with "excellent" performance evaluation to similar projects, and even set them as the benchmarking projects. In the case of sufficient PPP projects in practice, the Department of Finance can hire professional advisory bodies to analyze the group of PPP projects with "excellent" performance evaluation, and sum up rules from a large number of practices. On this basis, reasonable risk sharing scheme, contract templates, price adjustment formula and so on of a certain type of PPP projects should be improved, thereby providing basis for functional departments of the government to work well in project level; in addition, the decision-making mechanisms, procurement mechanisms, supervision policies, information disclosure policies and so on should be optimized continuously, thereby providing technical support for the Department of Finance to work well in strategic level.

4.3 Accountability investigation of PPP projects. The State Council No. 43 Document expressly stipulated that the government debt shall be placed under evaluation of political achievements as an inflexible standard, and responsibilities of the responsible persons shall be pursued in case of deviation from the reality, excessive borrowing, illegal borrowing or guarantee, illegal use of debt capital, debt guarantees, malicious evasion of debts and other behaviors. Therefore, the PPP projects with "poor" performance evaluation shall be subject to accountability investigation. A basic idea of performance improvement of public project management has been put forward in existing research, namely GMP (Governance Management Performance) analysis framework ${ }^{[4]}$. This paper argued that accountability investigation can be launched conversely along this chain: for the PPP projects with "poor" performance evaluation (corresponding to P), first of all, it is necessary to check whether government departments follow the "regulations" strictly to work in the whole process of the project 
(i.e., whether they do work right, corresponding to $\mathrm{M}$ ); the government departments or specific persons failed to fulfill due diligence shall be pursued of the responsibilities. If it is found that government departments are devoted to their duties, it should be considered whether the provisions and corresponding systems exist design defects (i.e. whether they do right work, corresponding to G); if it is found that relevant provisions or systems are not appropriate, the Department of Finance shall organize the persons of relevant government departments and experts to improve them, and constantly improve PPP legislation and actual operations in China. The accountability investigation of unfavorable PPP projects launched conversely based on the GMP analysis framework can ensure that "do right things correctly", and eventually lead to the success of PPP projects.

\section{Summary}

The legal way to relieve local debt and develop public welfare has been PPP. A large number of PPP projects will be appeared along with development of new type urbanization in China, therefore, the policy must be prepared by government. However, layer manage should be performance by government in order to achieve target orderly and efficiency. Only the decision, supervision, evaluate of performance and responsibility such as strategic level works are achieved by Department of Finance which act as manage PPP projects uniformly, the manage level work have opportunity be achieved smoothly.

\section{Acknowledgments}

Foundation: National Natural Science Foundation of China (71372110, 71472135)

\section{References}

[1] Gao H.Q., Liu Y.G., Qi X., Fu H.Y., Study of international practical VFM evaluation methods based on PPP : Take Britain, Germany and Singapore as examples, J. Project Management Technology, 9(2011)18-21.

[2] Yuan J.F., Ji C., Li Q.M., The Key Performance Indicators in International PPP Projects, J. Journal of Industrial Technological Econoomics, 6 (2012)109-120.

[3] Wang Y.M., Yan D.L., Study of PPP projects performance evaluation system based on balanced scorecard, J. Friends of Accounting, 2(2014)14-17.

[4] Du Y.L., Yin Y.L., Empirical study of the governance approach to improving the management performance of public projects: take enterprise construction agent projects as an example, J. China Civil Engineering Journal, 44 (2011)32-137. 